\title{
A AGROECOLOGIA NO SEMIÁRIDO: CAMINHO PARA A SUSTENTABILIDADE DAS ÁREAS SUSCEPTÍVEIS À DESERTIFICAÇÃO
}

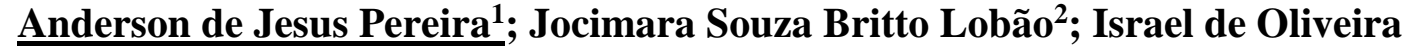 \\ Junior $^{3}$ \\ 1. Bolsista PROBIC/UEFS, Graduando em Agronomia, Universidade Estadual de Feira de Santana (UEFS), e-mail: \\ dinho_sa@hotmail.com \\ 2. Orientadora, Departamento de Ciências Humanas e Filosofia (DCHF), UEFS, e-mail: juci.lobão@gmail.com \\ 3. Participante do Grupo de Pesquisa CNPq Natureza, Sociedade e Ordenamento Territorial, DCHF, UEFS, e-mail: \\ iojjunior@gmail.com
}

PALAVRAS-CHAVE: Degradação ambiental; agricultura; impactos ambientais.

\section{INTRODUÇÃOO}

As discussões sobre a desertificação no Brasil remontam a década de 1970, quando Vasconcelos Sobrinho (1971) publicou a monografia Núcleos de Desertificação no Polígono das Secas (Matallo Junior, 2001). Com isso, iniciaram estudos para monitorar a desertificação em terras brasileiras, que tiveram um caráter pontual e de elucidar lacunas referentes ao processo. As pesquisas realizadas em todo o mundo evidenciaram que a desertificação é a degradação das terras dominadas pelo clima árido, semiárido e subúmido, e resultante das atividades humanas (ONU, 1997), como agropecuária, que geram instabilidades sociais, como o declínio da produtividade da terra.

No Brasil, existe preocupação em relação as atividades agropecuárias (Souza, 2006), porque a manutenção do equilíbrio clima-solo-vegetação é ameaçada por práticas e técnicas agrícolas convencionais empreendidas em um frágil ambiente. A intensa exploração ambiental ampliou a vulnerabilidade à desertificação de diversos municípios brasileiros localizados na Área Susceptível à Desertificação (ASD).

Como um processo de contraposição a ordem da agricultura convencional, alguns modos de produzir alternativos são pauta de discussão. Os debates promovem tipos de agriculturas alternativas, muitos à luz da Agroecologia. No discurso teórico sobre a Agroecologia é comum indicar a função social dela, que consiste na transição gradual e não linear de modelos de desenvolvimento rural e de agricultura convencionais para aqueles pautados na perspectiva da sustentabilidade (Caporal \& Costabeber, 2000, 2002, 2004). Gliessman (2000) indicou que a Agroecologia visa a aplicação de teorias fundamentadas nos princípios da ecologia, no intuito de gerar o manejo integrado dos sistemas ambientais, os agrossistemas. Isso decorre a partir da incorporação de técnicas e tecnologias produtivas no campo de bases sustentáveis, substituindo a produção, por exemplo, agroquímica (Caporal \& Costabeber, 2004), que constitui em um fator de desertificação.

Objetiva-se, por meio deste trabalho, discutir sobre a importância da Agroecologia como caminho de enfrentamento das causas e consequências da desertificação. Para tanto, realizou-se uma revisão bibliográfica para entender a teia de relações intrínsecas ao processo de degradação das terras secas, as principais práticas e técnicas engendradas na reprodução das atividades agrícolas da ASD do Brasil, os principais fatores de desertificação relacionado ao solo e algumas medidas para reverter o processo de degradação ambiental pautada na Agroecologia. 


\section{MATERIAIS E MÉTODO}

O estudo constitui-se em uma pesquisa bibliográfica, pois todo o embasamento para a arguição adquiriu-se por meio da fundamentação teórica sobre as produções científicas relacionadas ao processo de desertificação. Inicialmente, buscou-se realizar uma análise, seleção e crítica das discussões sobre os conceitos, causas e consequências e ações de enfrentamento da desertificação e temas afins na literatura científica.

As informações relacionadas à degradação das terras secas foram analisadas à luz da produção científica ambiental e pedológica do semiárido, na tentativa de entender e discutir as definições do processo de desertificação, dos fatores e efeitos do processo para o sistema ambiental. A partir daí, identificou-se as principais pressões e impactos ambientais resultantes da agricultura convencional relacionados à desertificação, para, após, identificar as propostas de mitigação e reversão fundamentadas na Agroecologia.

\section{RESULTADOS E DISCUSSÃO}

No contexto do desenvolvimento de atividades agrícolas, as principais causas da desertificação relacionam-se ao desmatamento das feições vegetais, por expor os solos às intempéries climáticas, instalar e/ou potencializar os processos erosivos e diminuir a biodiversidade, como pode ser observado no quadro 1 .

Quadro 1. Atividades agrícolas e degradação: síntese das causas e das consequências ambientais do uso da terra agrícola em espaços susceptíveis à desertificação

\begin{tabular}{|c|c|}
\hline $\begin{array}{l}\text { Atividades e } \\
\text { práticas agrícolas }\end{array}$ & Causas e consequências \\
\hline Monocultura & $\begin{array}{l}\text { Destruição das florestas e da biodiversidade genética; erosão dos solos; } \\
\text { contaminação dos recursos naturais; grande aplicação de fertilizantes inorgânicos, } \\
\text { necessidade de irrigação, que contribui com a salinização dos solos; o constante } \\
\text { controle químico de pragas, por impactar na perda da biodiversidade animal e } \\
\text { vegetal }\end{array}$ \\
\hline Desmatamento & $\begin{array}{l}\text { Perda da biodiversidade (com a destruição das florestas, o habitat natural de muitas } \\
\text { espécies torna-se escasso ou inexistente, contribuindo para a morte de muitos } \\
\text { animais podendo levar a extinção); erosão hídrica e eólica, enchente e } \\
\text { assoreamento dos rios, diminuição dos índices pluviométricos }\end{array}$ \\
\hline $\begin{array}{l}\text { Uso contínuo de } \\
\text { agrotóxicos }\end{array}$ & $\begin{array}{l}\text { Redução da biodiversidade biológica, contaminação do solo na camada superficial } \\
\text { e subterrânea, (o acúmulo de agrotóxicos no solo pode levar a absorção de } \\
\text { elementos minerais); contaminação da água na escala local e pode ocorrer o } \\
\text { bloqueio do sistema de defesa da planta; redução dos inimigos naturais }\end{array}$ \\
\hline $\begin{array}{l}\text { Emprego de } \\
\text { máquinas agrícolas }\end{array}$ & $\begin{array}{l}\text { Compactação do solo (redução da permeabilidade hídrica), pois a água da chuva, } \\
\text { ao encontrar uma superfície compactada, não consegue penetrar e escorre levando } \\
\text { consigo a camada superficial do solo e uma série de nutrientes essenciais, } \\
\text { ampliação da circulação de erosão e redução do crescimento radicular }\end{array}$ \\
\hline Irrigação & $\begin{array}{l}\text { Degradação do solo, esgotamento dos aquíferos, intrusão de água do mar em áreas } \\
\text { costeiras, salinização, erosão, contaminação do solo, escassez de água, afeta os } \\
\text { níveis hídricos de lagos, rios e, especialmente, lençóis de águas subterrâneas e a } \\
\text { alterações da paisagem }\end{array}$ \\
\hline $\begin{array}{l}\text { Agricultura } \\
\text { sequeiro }\end{array}$ & $\begin{array}{l}\text { Desestabilizar os agregados do solo, o que por sua vez irá facilitar o deslocamento } \\
\text { das partículas e reduzir a profundidade do solo, ou seja, a erosão, evaporação da } \\
\text { água do solo levando a escassez }\end{array}$ \\
\hline Queimadas & $\begin{array}{l}\text { Redução da biodiversidade biológica (flora, e fauna com menor mobilidade); } \\
\text { erosão; perda de matéria orgânica e de nitrogênio na manta morta e no horizonte } \\
\text { superficial do solo criação de crosta na parte superficial, risco de inundações, } \\
\text { alteração dos fluxos de água; eliminam bactérias e outros microrganismos que } \\
\text { compõem a microfauna do solo }\end{array}$ \\
\hline $\begin{array}{l}\text { Introdução de } \\
\text { espécies exóticas }\end{array}$ & $\begin{array}{l}\text { Redução das espécies nativas, a espécie introduzida pode se tornar uma praga; } \\
\text { perda da biodiversidade nativa; podem disputar o mesmo nicho ecológico }\end{array}$ \\
\hline
\end{tabular}


A desertificação tende a começar com o desmatamento que é um processo causado pelo desaparecimento das feições vegetais do bioma caatinga, no caso do Brasil, sendo o homem o seu principal gerador. A principal consequência constitui na perda da biodiversidade, com a destruição das florestas. O habitat natural de muitas espécies torna-se escasso ou inexistente, decorre na morte de muitos animais, e amplia o risco de extinção de espécies, sobretudo as endêmicas. Há impactos indiretos, como na redução do regime de chuvas e comprometimento da qualidade da água e erosão hídrica e eólica. A erosão é a mais grave das causas de degradação dos solos por sua irreversibilidade, pois causa um empobrecimento dos nutrientes, uma vez que a camada superficial do solo é a mais nutritiva; decorre na redução na profundidade do solum, diminuição da capacidade de retenção hídrica e de nutrientes. O processo leva a um declínio na fertilidade do solo e no crescimento e na produtividade das plantas; o solo recebe menos matéria orgânica, e o húmus mineraliza-se mais rapidamente, devido aos efeitos das elevadas temperaturas.

Como uma forma de contrapor os tipos hegemônicos de produção no campo, surgem as agriculturas alternativas, com diversas denominações, como orgânica, biológica, natural ecológica, permacultura. Cada uma delas fundamenta-se em filosofias, princípios, tecnologias, normas e regras, de acordo as correntes teóricas e metodológicas, mas nem todas seguem os fundamentos da agroecologia. As agriculturas alternativas oriundas da Agroecologia possuem uma base ecológica, porque busca a sustentabilidade em todas as etapas da produção, desde o manejo (Quadro 2) às práticas comerciais, o que distingue da agricultura convencional, agroquímica, etc.

Quadro 2. Atividades agrícolas e sustentabilidade: indicações da Agroecologia para reverter os impactos negativos ambientais

\begin{tabular}{|c|c|}
\hline $\begin{array}{c}\text { Práticas da } \\
\text { Agroecologia }\end{array}$ & Impactos positivos \\
\hline $\begin{array}{l}\text { Adubação } \\
\text { Orgânica }\end{array}$ & $\begin{array}{l}\text { Fornece os macros e micro nutrientes necessários e em doses proporcionais sem } \\
\text { excesso para as plantas, para que o metabolismo delas ocorra de forma } \\
\text { equilibrado, sem ocorrer acúmulos de substâncias solúveis e com possibilidade de } \\
\text { as tornarem mais resistentes as ações deletérias das plantas daninhas }\end{array}$ \\
\hline $\begin{array}{l}\text { Uso de espécies } \\
\text { nativas }\end{array}$ & $\begin{array}{l}\text { Cultivar plantas adaptadas as condições edafoclimáticas reinantes no bioma, pois } \\
\text { suportam os estresses motivado pelo ambiente }\end{array}$ \\
\hline $\begin{array}{l}\text { Manutenção da } \\
\text { cobertura de solo }\end{array}$ & $\begin{array}{l}\text { Utilizar a cobertura do solo, por meio de plantas vivas ou por cobertura morta, no } \\
\text { intuito de proteger a camada superficial da intensa radiação solar, evitar a perda } \\
\text { de água por evapotranspiração e reduzir os impactos causados pela gota da chuva }\end{array}$ \\
\hline $\begin{array}{l}\text { Formação } \text { de } \\
\text { quebra ventos }\end{array}$ & $\begin{array}{l}\text { Adicionar, no desenho do agroecossistema, espécies arbóreas e/ou arbustivas para } \\
\text { mitigar ou alterar a direção do vento, que refletem na minimização da transpiração } \\
\text { e dessecação das plantas, além de reduzir a erosão eólica }\end{array}$ \\
\hline $\begin{array}{l}\text { Controle biológico } \\
\text { de pragas }\end{array}$ & $\begin{array}{l}\text { Com a presença da biodiversidade de plantas, aumenta a atividade do controle } \\
\text { biológico e conservação dos inimigos naturais }\end{array}$ \\
\hline $\begin{array}{l}\text { Deposição de } \\
\text { matéria orgânica }\end{array}$ & $\begin{array}{l}\text { Melhora as propriedades químicas, físicas e biológicas do solo, para proporcionar } \\
\text { o crescimento radicular e o acúmulo de água no solo }\end{array}$ \\
\hline $\begin{array}{l}\text { Gessagem e } \\
\text { calagem }\end{array}$ & $\begin{array}{l}\text { Correção de acidez do solo e pode ser utilizado, eventualmente, para correção no } \\
\text { tratamento contra salinidade }\end{array}$ \\
\hline Policultivo & $\begin{array}{l}\text { Conservação da flora e fauna local, redução de doenças, de pragas, da competição } \\
\text { por água, por luz e por nutrientes; é necessário considerar as culturas escolhidas e } \\
\text { efeitos alelopáticos, rotação de culturas, mutualismo, diminuição e/ou controle de } \\
\text { plantas daninhas, melhor utilização dos nutrientes disponíveis no solo }\end{array}$ \\
\hline
\end{tabular}




\section{CONSIDERAÇÕES FINAIS}

O termo degradação está associado à utilização incorreta do patrimônio ambiental, denotando a ação humana como fator primordial para a desertificação. Em relação às atividades agrícolas e aos impactos no sistema solo do semiárido brasileiro, é comum encontrar na literatura científica os processos de desertificação associados à salinização, compactação, erosão dos solos, por constituir-se em fenômenos comuns às paisagens desertificadas.

Geralmente as pressões estão associadas às práticas do desmatamento e queimadas das feições vegetais da caatinga, utilização de máquinas agrícolas não adaptadas aos solos, emprego da irrigação sem respeitar as condições pedológicas, climáticas e hídricas. Em função disso, há uma interferência nos fatores biológicos dos solos, com a diminuição da fertilidade pedológica, razão pela qual ocorre a perda da biodiversidade vegetal, por interferir negativamente no desenvolvimento das plantas da caatinga, e dos cultivos agrícolas, o que gera um desequilíbrio ecológico, com efeitos nos componentes físicos, biológicos e sociais.

Existem caminhos técnicos para conduzir ao manejo das terras do semiárido, pautada na Agroecologia. A erosão, por exemplo, pode ser reduzida ou interrompida a partir da adição de matéria orgânica para melhorar a estrutura física, química e biológica do solo, para viabilizar a descompactação, aumentar a permeabilidade e retenção hídrica e a capacidade de troca catiônica, que regulariza o $\mathrm{pH}$, estimulam o crescimento e proliferação de microrganismos benéficos no solo, sendo estes responsáveis pela produção contínua de húmus e melhoramento da estrutura do solo.

\section{REFERENCIAS}

CAPORAL, F. R.; COSTABEBER, J. A. 2000. Agroecologia e desenvolvimento rural sustentável: perspectivas para uma nova Extensão Rural. Agroecologia $e$ Desenvolvimento Rural Sustentável. 1 (1): 16-37.

2002. Agroecologia: enfoque científico e estratégico para apoiar o desenvolvimento rural sustentável. Porto Alegre, EMATER/RS-ASCAR.

2004. Agroecologia: alguns conceitos e princípios. Brasília, DF, MDA/SAF/DATER-IICA.

GLIESSMAN, S. R. 2000. Agroecologia: processos ecológicos em agricultura sustentável. Porto Alegre, UFRGS.

MATALLO JUNIOR, H. 2001. Indicadores de desertificação: histórico e perspectivas. Brasília, DF, UNESCO.

ORGANIZAÇÃO DAS NAÇÕES UNIDAS (ONU).1997. Convenção das Nações Unidas de combate à desertificação nos países afetados por seca grave elou desertificação, particularmente na África. Brasília, DF: Ministério do Meio Ambiente.

SOUZA, M. J. N. 2006. A problemática ambiental: cenários para o bioma da Caatinga no Nordeste do Brasil. In: SILVA, J. B; LIMA, L. C.; DANTAS, E. W. C. (Orgs.). Panorama da Geografia brasileira II. São Paulo: Annablume.

VASCONCELOS SOBRINHO, J. 1971.Núcleos de desertificação no polígono das secas. In: I ICB. 